\title{
Clinical and serological characteristics of Ecuadorian patients with rheumatoid arthritis
}

\section{Carlos Ríos' \\ Génessis Maldonado² \\ Carlos Paredes ${ }^{2}$ \\ Christian Ferro ${ }^{3}$ \\ Mario Moreno ${ }^{4}$ \\ Claudia Vera ${ }^{3}$ \\ Sara Vargas ${ }^{5}$ \\ Wendy Calapaqui ${ }^{5}$ \\ Carlos Vallejo ${ }^{6}$}

'Rheumatology and Rehabilitation Center, Clinical Research Department, Guayaquil, Ecuador; ${ }^{2}$ Espíritu Santo University, Rheumatology Department, Samborondón, Ecuador; ${ }^{3}$ Santiago de Guayaquil Catholic University, Rheumatology Department, Guayaquil, Ecuador; ${ }^{4}$ Luis Vernaza Hospital, Rheumatology Service, Guayaquil, Ecuador; ${ }^{5}$ Ecuadorian Society of Rheumatology, Clinical Research Department, Guayaquil, Ecuador; ${ }^{6}$ Pontificia Catholic University of Ecuador, Rheumatology Department, Quito, Ecuador

Correspondence: Génessis Maldonado Espíritu Santo University, Km. 2.5 La Puntilla, Samborondón 09230I, Ecuador Email gcmaldonado@uees.edu.ec
This article was published in the following Dove Press journal:

Open Access Rheumatology: Research and Reviews

13 June 2017

Number of times this article has been viewed

Background: Rheumatoid arthritis (RA) is a systemic autoimmune inflammatory disease, wherein late diagnosis and treatment leads to deformities and disability.

Objective: The aim of the study was to assess and describe the clinical and immunological characteristics, activity status of the disease, and functional capacity in a cohort of Ecuadorian patients with RA.

Methods: This is a cross-sectional, descriptive study conducted on a population of patients with prediagnosed RA from public and private Ecuadorian rheumatology clinics. This study investigated 400 patients with a mean age of 50 years, $353(82.25 \%)$ of which were female.

Results: The study showed that $44.3 \%, 83.5 \%, 60.3 \%, 41.8 \%, 37.5 \%$, and $11.5 \%$ had an acute onset of the disease, symmetrical polyarthritis, morning stiffness exceeding $1 \mathrm{~h}$, dry eyes, dry mouth, and rheumatoid nodules, respectively. A total of $89.7 \%$ presented with positive rheumatoid factor, and $96.5 \%$ were anti-citrullinated protein antibody positive.

Conclusion: This is the largest Ecuadorian cohort of patients with RA; clinical features are similar to those of other Latin American populations.

Keywords: rheumatoid arthritis, epidemiology, Ecuador

\section{Introduction}

Rheumatoid arthritis (RA) is a systemic autoimmune, progressive, incapacitating, and multifactorial inflammatory disease. It most typically presents with bilateral and symmetrical polyarthritis, which causes joint pain and deformity, resulting in disability. Its extra-articular manifestations are heterogeneous and cover a wide range of affected organs; these manifestations are associated with a less favorable prognosis. ${ }^{1}$

Its chronic course is a cause of increased morbidity/mortality, resulting in the deterioration in the patient's quality of life.

Some factors, such as presence of rheumatoid factor, anti-cyclic citrullinated peptide (anti-CCP) antibodies, high disease activity, delay in consulting a specialist doctor, and therefore late diagnosis, have been considered representative of an unfavorable prognosis. $^{2}$

Diagnosis is clinical, based on the RA classification criteria established by the American College of Rheumatology (ACR) in 1987, which were updated in $2010 .^{3}$

Detailed assessment of patients with suspected RA is essential to confirm its diagnosis, monitor the patient, and provide a prognosis for the course of the disease. This includes the number of painful and swollen joints, assessment of the disease activity and pain using visual scales, assessment of functional capacity through approved 
questionnaires, assessment of acute phase reactants such as C-reactive protein (CRP), assessment of globular sedimentation rate, and analysis of structural damage through X-ray images of the hands. ${ }^{4}$

The progress of the disease can cause deformity and disability in patients with RA, which has become a public health problem principally in Latin America, where RA is becoming more and more frequent. ${ }^{5}$

The aim of the study is to assess and describe the clinical and immunological characteristics, activity status of the disease, and functional capacity in a cohort of Ecuadorian patients with RA.

\section{Patients and methods}

A cross-sectional, descriptive study was conducted on a population of Ecuadorian patients with a preexisting diagnosis of RA in accordance with the ACR 1987 classification criteria from public and private rheumatology clinics in the cities of Quito, Guayaquil, Manta, and Portoviejo. ${ }^{6}$

The patients signed an informed consent form, which reflects the approval of the clinical study according to article 361 of the Political Constitution of the Republic of Ecuador, article 7 of the Organic Health Law, and article 15-16 of the Code of Medical Ethics of Ecuador. The study was approved by the Ethics and Teaching Committee of the Centro de Reumatología y Rehabilitación (CERER) with a registration number: No.001/2015; Folio 01: Book of Acts No.1. Patient anonymity of data was respected throughout the entire investigative process, and it was explained to the participants that the data collected would be used solely for the study.

A database was created to collect patient information, including the following variables: demographic data, clinical manifestations, comorbidities, habits, and treatment. To stratify disease activity, the Disease Activity Score-28 with C-reactive protein (DAS-28-CRP) was used, the number of painful joints among 28 joints was assessed, and visual analog scale (VAS) of pain was completed by the patient. The DAS-28-CRP was calculated by using the DAS score program version $1.1 .^{7}$ Depending on the values obtained, the patient was classified as in remission (score lower than 2.6), with low activity (2.6-3.2), with moderate activity (3.2-5.1), and with high disease activity (higher than 5.1).

The Spanish version of the Health Assessment Questionnaire Disability Index (HAQ-DI), approved in 1993, was used to assess the patient's functional capacity and establish their degree of disability. This questionnaire has eight categories and a score between 0 and 3 . Based on the degree of difficulty a patient presents in each activity, a score of more than
1.25 is considered as disability, and a score of 3 as severe disability. ${ }^{7}$ The questionnaire was completed by the patients in their native language (Spanish).

The data was analyzed in the SPSS V.22 statistical program (IBM, Armonk, NY, USA), which was used to calculate measures of central tendency (mean) for quantitative variables and descriptive statistical measures, such as absolute and relative frequencies, for qualitative variables; also, the odds ratio (confidence interval: 95\%) with Pearson correlation and Fisher correction in the study group was calculated. Values with two-tailed $p<0.001$ were considered statistically significant.

\section{Results}

We investigated 400 patients, of whom 353 and 47 (11.75\%) were females and males, respectively. The mean age was 50 years (18-90 years).

A total of $93.75 \%(375), 3.5 \%(14), 1.5 \%$ (6), and 1.25\% (5) of the patients were mixed race, white, and indigenous Afro-Ecuadorian, respectively.

Depending on the health system the patients came from, $32 \%$ (129), 23\% (92), and 45\% (179) received private, state, and mixed care (hospital and private care), respectively.

The study showed that 55.75\% (223), 15.5\% (62), 12\% (48), 8.5\% (34), 8.25\% (33) were married, single, widowed, divorced, and cohabiting, respectively (Table 1).

The mean age of onset of the disease was 41 years (10-89 years), and the mean time taken before the first appointment with the specialist was 29 months (0-332 months), with a mean monitoring time of 52 months (0-504 months).

Depending on the place of the origin sector, $11.75 \%$ (47) and $88.25 \%$ (353) were from the city and country areas, respectively.

With regard to occupational activities, 53.5\% (214), 40\% (160), 6\% (24), and 0.5\% (2) were performing domestic chores, working in different fields, unemployed, and students, respectively.

The study also showed that 9.5\% (38), 7.5\% (30), 0.5\% (2) were active smokers, alcoholic beverage drinkers, and taking illegal/illicit drugs, respectively.

Depending on the characteristics of the disease, $44.3 \%$ (177) started with an acute onset, 55.5\% (222) started gradually, 83.5\% (334) presented symmetrical polyarthritis, $11.8 \%$ (47) asymmetrical polyarthritis, 5.3\% (21) oligoarthritis, and $0.3 \%$ (1) monoarthritis.

Depending on the symptomatology, $60.3 \%$ (241), $48.5 \%$ (194), 41.8\% (167), 37.5\% (150), 22.8\% (91), 35.5\% (142), $11.5 \%$ (46), 3.3\% (13), and 30.8\% (123) reported morning 
stiffness lasting more than $1 \mathrm{~h}$, fatigue, dry eyes, dry mouth, fever, myalgias, rheumatoid nodules, Raynaud's phenomenon, and weight loss, respectively.

Table I General characteristics

\begin{tabular}{|c|c|c|}
\hline Demographic details & $\mathbf{n}$ & $\%$ \\
\hline Mean age (range), years & \multicolumn{2}{|c|}{$50(18-90)$} \\
\hline Male & 47 & 11.75 \\
\hline Female & 353 & 88.25 \\
\hline \multicolumn{3}{|l|}{ Ethnic group } \\
\hline White & 14 & 3.5 \\
\hline Mixed & 375 & 93.75 \\
\hline Afro-Ecuadorian & 5 & 1.25 \\
\hline Indigenous & 6 & 1.50 \\
\hline \multicolumn{3}{|l|}{ Medical care } \\
\hline State & 92 & 23 \\
\hline Mixed & 179 & 45 \\
\hline Private & 129 & 32 \\
\hline \multicolumn{3}{|l|}{ Civil status } \\
\hline Single & 62 & 15.50 \\
\hline Married & 223 & 55.75 \\
\hline Cohabiting & 33 & 8.25 \\
\hline Divorced & 34 & 8.50 \\
\hline Widowed & 48 & 12 \\
\hline \multicolumn{3}{|l|}{ Place of origin } \\
\hline City & 47 & 11.75 \\
\hline Country & 353 & 88.25 \\
\hline \multicolumn{3}{|l|}{ Occupation } \\
\hline Working & 160 & 40 \\
\hline Not working & 24 & 6 \\
\hline Homemakers & 214 & 53.50 \\
\hline Students & 2 & 0.50 \\
\hline \multicolumn{3}{|c|}{ Initial diagnosis and monitoring of the patient, months (range } \\
\hline Age at onset of the disease & \multicolumn{2}{|c|}{$41(10-89)$} \\
\hline $\begin{array}{l}\text { Time before appointment with the } \\
\text { specialist }\end{array}$ & \multicolumn{2}{|c|}{$29(0-332)$} \\
\hline Monitoring time & \multicolumn{2}{|c|}{$52(0-504)$} \\
\hline
\end{tabular}

The study group's comorbidities were hypertension, gastric disease, diabetes, hypothyroidism, allergies, and neoplasia, accounting for: $23.8 \%$ (95), 28.5\% (114), 23.8\% (95), $15.3 \%$ (61), $10.5 \%$ (2), and 1.3\% (5), respectively (Figure 1).

Disease activity score, calculated with the DAS-28-CRP, had a mean value of 3.37 (0.67-7.59) (Figure 2).

Based on these results, $35.5 \%$ (142) were in remission, $16.8 \%(67)$ had low disease activity, $32.8 \%$ (131) had moderate activity, and $15 \%(60)$ had high activity. The mean number of painful and swollen joints was approximately 5 (0-28) and 4 (0-28), respectively.

The mean VAS reported by the patients was $3.9(0-10)$, whereas the VAS measured by the doctor was $3.4(0-10)$.

The mean HAQ-DI disability questionnaire score was 0.8 (0-3), and $66 \%$ (264) of the study population had no disability, whereas $34 \%$ (136) experienced some degree of disability, with $27 \%$ (108) and $7 \%$ (28) being functional and severe, respectively (Figure 3).

Laboratory results showed that 8.3\% (33), 6\% (24), 2.3\% (9), 5.3\% (21), 89.7\% (270/301), and 96.5\% (193/200) of the study population had leukocytosis, thrombocytosis, thrombocytopenia, anemia, positive rheumatoid factor, and positive anti-CCP, respectively.

Depending on the treatment, $94.75 \%$ (379), $18 \%$ (72), $78.3 \%$ (313), $4.3 \%$ (17), $7.8 \%$ (31), $73.5 \%$ (294), and $66.5 \%$ (266) were administered disease-modifying antirheumatic drugs (DMARD), antimalarials, methotrexate, sulfasalazine, leflunomide, corticoids, and nonsteroidal anti-inflammatory drugs, respectively.

Of the total population, $12.5 \%$ (50) were administered biologic drugs: $4.7 \%$ (19) etanercept, $2.75 \%$ (11)

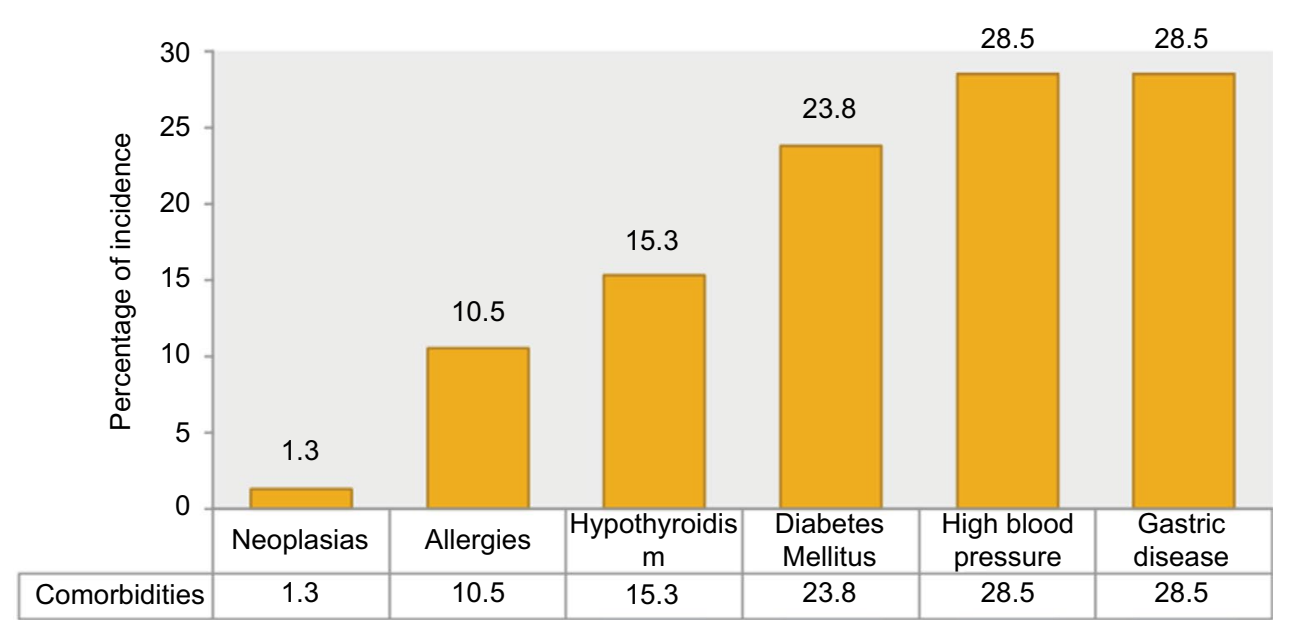

Figure I Comorbidities of patients with RA.

Abbreviation: RA, rheumatoid arthritis. 


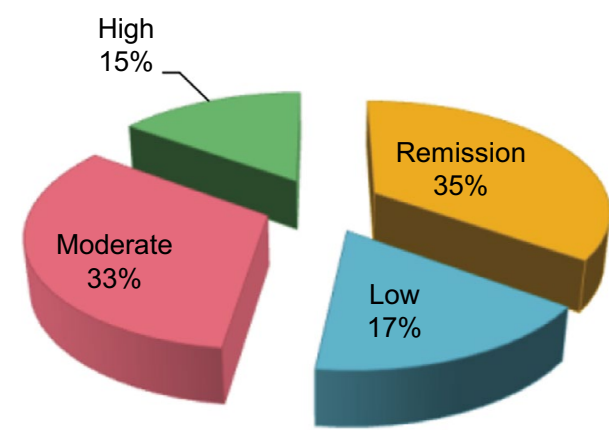

Figure 2 Determination of disease activity using DAS-28-CRP. Abbreviation: DAS-28-CRP, Disease Activity Score-28 with C-reactive protein.

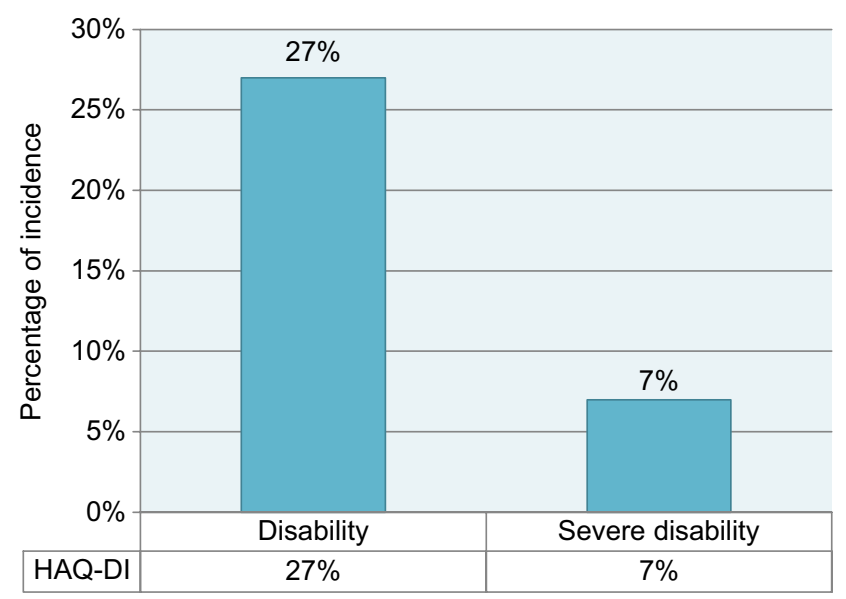

Figure 3 Determination of disability in patients with RA, using HAQ-DI questionnaire.

Abbreviations: HAQ-DI, Health Assessment Questionnaire Disability Index; RA, rheumatoid arthritis.

tocilizumab, 2\% (8) rituximab, 1.75\% (7) adalimumab, and $1.3 \%$ (5) Infliximab.

\section{Discussion}

RA is a chronic systemic autoimmune inflammatory disease of unknown etiology that most frequently affects females in the reproductive age. It is characterized by polyarticular inflammation of the small and large joints, with systemic involvement. ${ }^{1}$

The symptomatology and serology of this disease vary between different countries. In Ecuador, no epidemiological studies or data described the clinical and serological characteristics of Ecuadorian patients with RA.

The results obtained from this sample of Ecuadorian patients with RA show data similar to those obtained from the Latin American patient cohort, with early RA in the GLADAR (Grupo Latino Americano de Estudio de Artritis Reumatoidea [Latin American Rheumatoid Arthritis Study Group]) study in 2006, ${ }^{7}$ wherein 51 Ecuadorian patients also participated among patients from other countries.
In both studies, RA most frequently affected females $\left(88 \%\right.$ Ecuador vs $\left.85 \% \mathrm{GLADAR}^{8}\right)$. The mean age for onset of the disease was in the fourth decade (41 years for Ecuador vs 46 years for GLADAR). The disease presented in the majority of patients as symmetrical polyarthritis $(84 \%$ Ecuador vs 95\% GLADAR). Fatigue presented similar values in both studies (49\% Ecuador vs $43 \%$ GLADAR) for the manifestations, whereas some differences were observed for other manifestations, perhaps due to the monitoring time of these patients ( 52 weeks); for example, the presence of Sicca syndrome was more prevalent in the Ecuadorian population compared with that in the GLADAR study (42\% Ecuador vs $14 \%$ GLADAR), as were myalgias (36\% Ecuador vs $11 \%$ GLADAR) and rheumatoid nodules (12\% Ecuador vs $6 \%$ GLADAR).

The frequency of rheumatoid factor in the Ecuadorian population was higher than that in the GLADAR group $(90 \%$ Ecuador vs $76 \%$ GLADAR), which might be because this study only included patients with a preexisting diagnosis of RA. Finally, the results for administering disease-modifying drugs were similar in both population groups (95\% Ecuador vs $92 \%$ GLADAR), with methotrexate as the most common drug used for treatment. 9,10

In Argentina, two studies have been conducted investigating the prevalence of RA. Spindler et $\mathrm{al}^{11}$ studied a cohort of 695 patients with RA, wherein $86 \%$ were females, a value similar to this study ( $88 \%$ Ecuador vs $86 \%$ Argentina), with a mean age of 45 years at diagnosis (41 Ecuador vs 45 Argentina), with a total prevalence of 1.97 per $1,000(95 \%$ CI, 1.8-2).

Soriano et al $^{12}$ also had similar findings in their studies of RA in the Hospital Italiano de Buenos Aires (Buenos Aires Italian Hospital), where they also studied the incidence rate, which was 2.4 per 10,000 people/yr; RA was higher in females (3.3 per 10,000 people/yr) than in males (1.1 per 10,000 people/yr).

Remembering that the prognosis for this disease depends first on its early diagnosis and treatment is important. Houssien et $\mathrm{al}^{8}$ showed that patients being referred to a rheumatology clinic within the first year after the onset of symptoms had improved functional capacity. ${ }^{5}$ They, and other studies, have shown the importance of administering early treatment in patients with RA and concur that a delay of 3 months in starting an appropriate treatment decreases the chances of remission from arthritis. ${ }^{13}$

In our population, the delay in obtaining an appointment with the specialist was 29 months. Van der $\operatorname{Linden}^{14}$ et al studied the relationship between the total delay from the 
onset of symptoms to an appointment with the rheumatologist (including delays on the patient's part, accessing primary health care, and providing care on the rheumatologist's part), joint damage, and the probability of achieving remission. They found that $69 \%$ of the patients with RA were provided care after 12 weeks or more; this was linked with a hazard ratio of 1.87 of not achieving remission free of DMARD and 1.3 more chance of greater joint damage in 6 years compared with the group who were provided care within the first 12 weeks.

Guevera et $\mathrm{al}^{15}$ studied a cohort of 52 patients with a preexisting diagnosis of RA with mean time of 10.9 years affected by the disease; $82.7 \%$ of the patients were antiCCP positive, and $82.7 \%$ were positive for rheumatoid factor.

Corominas et $\mathrm{al}^{16}$ analyzed the diagnostic and therapeutic delay in RA and its relationship with health care departments in Catalunya. He found that the mean time from the onset of symptoms to the prescription of a disease-modifying drug in patients with RA was 11 months and that those patients who visited health care departments, such as clinics specializing in primary health care and arthritis, were treated sooner with disease-modifying drugs.

Another study with similar results is the ESORDIG ${ }^{17}$ study conducted in Greece, which concludes that an early appointment with the rheumatologist and combined therapy with DMARDs are linked with a better prognosis for the disease.

Results similar to those in our study were obtained in Raza et al's ${ }^{18}$ study. They studied 482 patients with RA from 10 centers and obtained a mean delay of 24 weeks from the onset of symptoms to an appointment with a rheumatologist. They concluded that despite some centers attempting to minimize the delays, more intervention is required to ensure early treatment.

In 2005, a Peruvian study describing the epidemiological aspects of RA in patients in a Rheumatology Department at the Hospital Nacional Guillermo Almenara Irigoyen de Salud (Guillermo Almenara Irigoyen National Hospital of Health) in Lima identified 661 patients with RA not using biologic drugs, with a mean age of 44.5 ; $91.68 \%$ were positive for rheumatoid factor, a value similar to the Ecuadorian cohort $(90 \%){ }^{19}$

Based on the disease activity assessed by DAS-28-CRP, $47.8 \%$ of the population studied presented activity between moderate and severe. Based on the assessment of the patients' functional capacity measured by HAQI, $37 \%$ of the population presented disability, including severe disability. This data reflected the high aggressiveness of the disease and the significant deterioration in the quality of life of the cohort studied.

\section{Conclusion}

The population studied is the largest cohort of patients with RA in Ecuador. The clinical characteristics did not differ greatly from populations in other studies, considering that descriptive studies of this disease are reported in Latin America, with the biggest probably being the GLADAR study, which revealed a situation very similar to that in Ecuador.

The conclusion must also be drawn that the cohort analyzed showed a very active, as well as incapacitating, disease, given that nearly $50 \%$ of the patients presented DAS-28 levels, which indicated activity between moderate and sever. This figure may well be related to the mean delay of 29 months in being assessed by a rheumatologist, and therefore a late diagnosis and treatment.

\section{Acknowledgments}

We acknowledge Maria Jose Intriago, Claudia Aguirre, Jenny Cárdenas, Víctor Avila from Universidad de Especialidades Espíritu Santo; Dr Rafael López, Dr Jose Martínez, Dr Nelson Córdova from Hospital Luis Vernaza; Dr Letty Moreno from Rheumatology and Rehabilitation Center and Dr Jose Nuñez, Dr Ivonne Quezada from Ecuadorian Society of Rheumatology for their contribution to the study.

\section{Disclosure}

The authors report no conflicts of interest in this work.

\section{References}

1. Maldonado-Cocco J, Citera G. Reumatología. 1era. Edic. Azurras; 2010

2. Villaverde García V, Balsa Criado A. Factores pronósticos de la artritis reumatoide. Rev Esp Reum. 2002;29(1):10-15.

3. Aletaha D, Neogi T, Silman A, et al. 2010 Rheumatoid arthritis classification criteria: an American College of Rheumatology/European League Against Rheumatism collaborative initiative. Ann Rheum Dis 2010;69(9):1580-1588.

4. Sociedad Española de Reumatología. Clinical practice guideline for the management of Rheumatoid Arthritis in Spain. 2011; Available from: http://www.ser.es/wp-content/uploads/2016/01/ GUIPCAR_31Marzo2012_ENG.pdf.

5. Sociedad Argentina de Reumatología. Guías Argentinas de Práctica Clínica en el Tratamiento de la Artritis Reumatoidea. Rev Argent Reumatol. 2008;19(3):293.

6. Arnett F, Edworthy S, Bloch D, et al. The American Rheumatism Association 1987 revised criteria for the classification of rheumatoid arthritis. Arthritis Rheum. 1988;31(3)315-324.

7. Cardiel M, Abello-Banfi M, Ruiz-Mercado R, Alarcon-Segovia D. How to measure health status in rheumatoid arthritis in non-English speaking patients: validation of a Spanish version of the Health Assessment Questionnaire Disability Index (Spanish HAQ-DI). Clin Exp Rheum. 1993;11(2):117-121.

8. Cardiel MH. First Latin American position paper on the pharmacological treatment of rheumatoid arthritis. Rheumatology (Oxford). 2006;45 Suppl 2:ii7-ii22. 
9. Cardiel MH; PANLAR, GLADAR. First Latin American position paper on the pharmacological treatment of rheumatoid arthritis. Rheumatology. 2006;45:ii7-ii22.

10. Cardiel M, Pons-Estel B, Sacnun M, et al. Treatment of early rheumatoid arthritis in a multinational inception cohort of Latin American patients: the GLADAR experience. J Clin Rheumatol. 2012;18(7):327-335.

11. Spindler A, Bellomio V, Berman A. Prevalence of rheumatoid arthritis in Tucuman, Argentina. J Rheumatol. 2002;29:1166-1170.

12. Soriano E, Carrión J, Schpillberg M, Figar S, Imamura P, Cattogio L. Incidence and prevalence of rheumatoid arthritis in health management organization in Argentina. Rheumatology. 2003;42(1):130.

13. Sørensen J, Hetland M. Diagnostic delay in patients with rheumatoid arthritis, psoriatic arthritis and ankylosing spondylitis: results from the Danish nationwide DANBIO registry. Ann Rheum Dis. 2015;74(3):e12.

14. van der Linden M, le Cessie S, Raza K, et al. Long term impact of delay in assessment of patients with early arthritis. Arthritis Rheum. 2010;62(12):3537-3546.
15. Guevara S, Ochoa M, Vintimilla J, et al. Antígenos HLA de clase II en pacientes con artritis reumatoide ecuatorianos y asociación con el factor reumatoide, anticuerpos anti-citrulinados y nódulos reumatoides. Rev la Fac Ciencias Médicas la Univ Cuenca. 2014;32(1):66-77.

16. Corominas H, Narvaéz J, Díaz-Tórne C, et al. Diagnostic and therapeutic delay of rheumatoid arthritis and its relationship with health care devices in Catalonia. The AUDIT study. Reum Clin. 2016;12: 146-150.

17. Andrianakos A, Trontzas P, Christoyannis F, et al. Prevalence and management of rheumatoid arthritis in the general population of Greece--the ESORDIG study. Rheumatology. 2006;45(12):1549-1554.

18. Raza K, Stack R, Kumar K, et al. Correction: delays in assessment of patients with Rheumatoid Arthritis: variations across Europe. Ann Rheum Dis. 2011;70:1822-1825.

19. Acevedo-Vásquez E. Algunos aspectos de la artritis reumatoide en Perú. Rev Soc Peru Med Interna. 2012;25(1):31-37.

\section{Publish your work in this journal}

Open Access Rheumatology: Research and Reviews is an international, peerreviewed, open access journal publishing original research, reports, editorials, reviews and commentaries on all aspects of clinical and experimental rheumatology in the clinic and laboratory including the following topics: Pathology, pathophysiology of rheumatological diseases; Investigation, treatment and management of rheumatological diseases; Clinical trials and novel pharmacologi$\mathrm{cal}$ approaches for the treatment of rheumatological disorders. The manuscript management system is completely online and includes a very quick and fair peer-review system, which is all easy to use. Visit http://www.dovepress.com/ testimonials.php to read real quotes from published authors. 